\title{
Immune Response in Holstein-Zebu Cross and Zebu Calves Vaccinated with Bacillus Calmette-Gu é rin (BCG) at Bako Agricultural Research Centre, Western Ethiopia
}

\author{
Ketema Tafess ${ }^{1}$ and Gobena Ameni ${ }^{2 *}$
}

${ }^{1}$ Department of Immunology and Molecular Biology, School of Biomedical and Laboratory Sciences, College of Medicine and Health Science, Gondar University, PO box 196, Gondar, Ethiopia

${ }^{2}$ Aklilu Lemma Institute of Pathobiology, Addis Ababa University, PO Box 1176, Addis Ababa, Ethiopia

\begin{abstract}
Background: Mycobacterium bovis (M. bovis) bacillus Calmette-Gue'rin (BCG) currently remains the only licensed vaccine for the prevention of tuberculosis. The purpose of this study was to evaluate immune responses in calves vaccinated with $B C G$ in western Ethiopia.

Methods: Twelve Holstein-zebus cross breed calves (six vaccinated with $0.5 \mathrm{ml}$ of $1 \times 106$ CFU of BCG and six controls) and nine pure zebu calves (five vaccinated with $0.5 \mathrm{ml}$ of $1 \times 106 \mathrm{CFU}$ of BCG and four controls) were used in this study. Immune responses were monitored for 23 weeks post vaccination using gamma interferon (IFN- $y$ ) assay and comparative intra-dermal tuberculin test to assess cellular response, and enzyme-liked immunosorbant assay (ELISA) to measure antibody response.

Results and interpretation: IFN-y response was observed starting from week 2, attaining its peak at week 4 post vaccination after which a fall in the response of IFN- $\gamma$ was observed attaining a constant concentration from week 8 onwards. The mean IFN-y response (OD450nm: Mean \pm SEM, $0.205 \pm 0.018)$ in vaccinated calves was significantly (tcal=2.85, $\mathrm{P}<0.05$ ) higher than the non-vaccinated calves (Mean $\pm \mathrm{SEM}, 0.168 \pm 0.008$ ) at 4 th week post vaccination. Within the vaccinated group, the mean IFN-y response was significantly (tcal $=3.01, P<0.05)$ greater in cross breed (Mean \pm SEM, $0.217 \pm 0.021$ ) than in zebu breeds (Mean \pm SEM, $0.194 \pm 0.015$ ) at 4th week post vaccination. On the other hand, no detectable antibody response was observed in vaccinated and non-vaccinated calves while the mean of skin thickness following skin test was significantly $(P<0.05)$ higher in vaccinated calves than in non-vaccinated calves 23 weeks post vaccination.
\end{abstract}

Conclusion: BCG induced IFN-y responses in both Holstein-zebu cross and zebu calves although stronger IFN-y response was observed in Holstein-zebu cross breed as compared to the response in zebu, which could suggest the possibility of using BCG for the control of bovine tuberculosis in Ethiopia.

Keywords: Immune response; Holstein-zebu cross breed; Zebu breed; BCG; Vaccination

\section{Background}

Growth in the number of the rural population of Ethiopia has lead to expansion of land for crop production, which computes for grazing land and hence necessities for intensification of animal production unlike the decades experiences of extensive animal production system. Besides, demographic growth and urbanization contribute to the increasing demand for milk, meat, egg, and other animal products. This requires for concomitant intensification of animal husbandry and the development of peri-urban systems of livestock productions. Intensification animal production creates conducive environment for the transmission of Mycobacterium bovis (M. bovis) between cattle. Moreover, the encroachment of people and livestock into wildlife areas because of pressure on land for grazing and human settlement has magnified the risk of $M$. bovis transmission among wildlife, livestock and humans.

M. bovis is the primary cause of bovine tuberculosis, which causes economic losses of approximately $\$ 3$ billion annually worldwide in agricultural sector [1]. In addition, bovine tuberculosis has severe implication for animal welfare and animal health since it causes reduced productivity and premature death in cattle [2]. On top of this, $5-15 \%$ of human TB was estimated to be caused by the zoonotic transmission of $M$. bovis from infected animal to humans through ingestion of food of animal origin or aerosol inhalation due to close physical contact with infected animal [3]. This implies that control of bovine tuberculosis can alleviate its economic and public health impacts. However, although $60 \%$ of the African, $47 \%$ of the Asian, and $38 \%$ of the Caribbean countries have reported the occurrence of bovine tuberculosis from sporadic to enzootic level, only a few countries apply the test and slaughter control strategy because of economic and social implications of the test and slaughter control strategy [4]. Studies conducted in Ethiopia on bovine tuberculosis reported that the prevalence of bovine tuberculosis ranges from $3.4 \%$ to $50 \%$ depending on cattle husbandry system; relatively lower in extensive husbandry but higher in intensive husbandry system [5-11]. Thus such epidemiological data warrant for the launching of appropriate control strategy so that the impact of the disease is minimized. As test and slaughter is expensive for countries like

*Corresponding author: Gobena Ameni, Aklilu Lemma Institute of Pathobiology, Addis Ababa university, PO Box 1176, Addis Ababa, Ethiopia, E-mail: gobenachimdi2009@yahoo.co.uk

Received August 16, 2011; Accepted August 22, 2011; Published August 25, 2011

Citation: Tafess K, Ameni G (2011) Immune Response in Holstein-Zebu Cross and Zebu Calves Vaccinated with Bacillus Calmette-Guérin (BCG) at Bako Agricultural Research Centre, Western Ethiopia. J Vaccines Vaccin 2:122. doi:10.4172/2157 7560.1000122

Copyright: (c) 2011 Tafess K, et al. This is an open-access article distributed unde the terms of the Creative Commons Attribution License, which permits unrestricted use, distribution, and reproduction in any medium, provided the original author and source are credited. 
Ethiopia, control by vaccination is a better control option. Presently, $M$. bovis bacillus Calmette-Guerin (BCG) is the only vaccine that is being used for the control of tuberculosis. Its potential application for the control of bovine tuberculosis has been evaluated in different regions of the world with various levels of protection. The present study was undertaken to evaluate immune response in Friesian-zebu cross and zebu calves vaccinated with BCG in field condition in Ethiopia.

\section{Materials and Methods}

\section{Experimental animals and their management}

The study was conducted at Bako Agricultural Research Centre. Bako Agricultural Research Centre is located in western Ethiopia at $258 \mathrm{~km}$ from Addis Ababa. One of the mandates of the Centre is to cross breed exotic such as Holstein or Jersey with the Horro breed (zebu) so that cross-bred cattle is produced and distributed to the farmers in western Ethiopia. The Centre was ideal for undertaking the present study as it keeps Holstein-zebu cross and zebu calves under a similar cattle husbandry. Calves were separated from their dams at birth, weighed and fed colostrum for the first 5 days from the bucket. Thereafter, whole milk and a concentrate mix were feed to the calves until weaning. Then calves were kept indoors (day and night) until six months of age in individual pens, except for about 2 hours of exercise in a nearby paddock every day.

Twelve crosses (Holstein-zebu) and nine zebu male calves with age ranging from 2-4 weeks were used for this experiment. Then six crossbred and five zebu calves were selected randomly and vaccinated by subcutaneous injection with $0.5 \mathrm{~mL}$ of $1 \times 10^{6} \mathrm{CFU}$ of BCG Danish (Staten Serum Institute, Denmark, kindly donated by Professor Martin Vordermeier, TB Research Group, Veterinary Laboratories Agency, UK), which was supplied as freeze-dried preparation and re-constituted in Sauton's medium as per the supplier's instructions. The remaining six cross-bred and four zebu calves were used as control in their respective order. The control (non-vaccinated) and vaccinated animals were sampled at various time points of post vaccination to analyze in vitro immune responses. All calves included in the study were checked for in vivo delayed type hypersensitivity at the end of the experiment.

\section{Blood sample collection schedule}

Blood samples were collected from each of the vaccinated and control calf aseptically from jugular vein using disposable needles and vacutainer tubes. For IFN- $\gamma$ assaying, blood samples were collected into heparinized vacutainers at weeks $0,2,4,8,13,18,23$ for while for serum extraction blood samples were collected into plain vacutainers at weeks $3,5,8,13,18,23$ for antibody detection

\section{Whole-blood culture and IFN- $\gamma$ assay}

Whole blood was dispensed at a $250 \mu$ l volume into the wells of 96 well flat-bottom culture plates. Antigens were added in $25 \mu \mathrm{l}$ aliquots to give the following final assay concentrations: avian PPD, 10 $\mu \mathrm{g} /$ $\mathrm{ml}$; bovine PPD, $10 \mu \mathrm{g} / \mathrm{ml}$; and saline $(25 \mu \mathrm{l})$ was used as negative controls. After 48 hours incubation at $37^{\circ} \mathrm{C}$ in a humid $5 \% \mathrm{CO}_{2}$, plasma supernatants were harvested and transferred to a 96-well plate and stored at $-20^{\circ} \mathrm{C}$ until tested for IFN- $\gamma$ assay. Levels of IFN- $\gamma$ in the supernatants were measured by an enzyme-linked immunosorbent assay by the bovine IFN- $\gamma$ (Bovigam) test kit (BOVIGAM ${ }^{\mathrm{m}}$, CSL Animal). Before the running the assay, all reagents were kept at room temperature and the freeze dried components were reconstituted. Thereafter $50 \mu \mathrm{l}$ of green diluents was added into the required wells.
And $50 \mu$ l of thawed plasma supernatant were added into the wells and properly mixed with the green diluents. After 60 minutes incubation at room temperature, the contents of the wells were removed and the wells were washed with wash buffer six times and dried. Thereafter, $100 \mu \mathrm{l}$ freshly prepared conjugate was mixed with blue diluents was added into each well. This was followed by incubation for 60 minutes at room temperature. Then, the contents were removed and the plates were washed six times with wash buffer. Following this, $100 \mu$ freshly prepared enzyme substrate solution was added into the wells and incubated for 30 minutes at room temperature in the dark. Thereafter, $50 \mu \mathrm{l}$ enzyme stopping solution was added into each well to stop the reaction. Finally, optical density (OD) was determined at $450 \mathrm{~nm}$ using plate reader (Titertek, Multiscan plus version 1.4, by joint venture Company of lab. system and row laboratory, Finland).

\section{Enzyme-linked immunosorbent assay}

Enzyme-linked immunosorbent assay was performed following the procedures described earlier [26]. Briefly, immunoplate Maxisorp (NUNC, Copenhagen, Denmark) 96 well plates were coated with MPB83 at $2 \mu \mathrm{g} / \mu \mathrm{l}$ and PPDb at $50 \mu \mathrm{l} / \mathrm{ml}$. The antigens were diluted

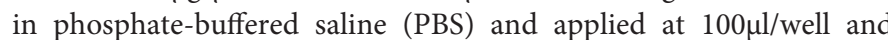
incubated at room temperature over night. The plates were then blocked with PBS containing $2 \%$ bovine serum albumin (BSA). Prior to use, antigen-coated plates were washed extensively with PBS containing 0.1\% Tween20 (PBS-T). Serum samples were diluted 1:100 in PBS containing $2 \%$ BSA and added into wells duplicate manner. Plates were incubated for $2 \mathrm{~h}$ at room temperature and then washed extensively with PBS-T. Bound antibodies were detected by incubation with horseradish-peroxdase (HR)-sheep anti-bovine IgG-at a dilution 1:5,000 in PBS-containing $2 \%$ BSA for $1 \mathrm{~h}$ at room temperature. Then the plates were extensively washed with PBS-T, $100 \mathrm{ml}$ of substrate solution (1:1 Chromogen and substrate buffer) were added into each well. Plates were incubated for another 20 minutes at room temperature, and colour development were stopped by addition of 100 $\mu \mathrm{l}$ of $0.5 \mathrm{M} \mathrm{H}_{2} \mathrm{SO}_{4}$ per well. Optical density at $450 \mathrm{~nm}$ (OD450) was measured with an automatic micro plate reader (Spectra Shell; Tecan).

\section{Comparative intradermal tuberculin test}

Twenty three weeks after vaccination, antigen-specific recall responses of calves were evaluated in vivo using comparative intradermal tuberculin test (CIDT). Briefly, two sites on the skin on the right side of the mid-neck of the animals, $12 \mathrm{~cm}$ apart, were shaved, and skin thicknesses were measured with a calliper. One site was injected with an aliquot of $0.1 \mathrm{ml}$ of $2,500-\mathrm{IU} / \mathrm{ml}$ bovine purified protein derivative (PPD) (Veterinary Laboratories Agency, Weybridge, UK) into the dermis, and the other was similarly injected with $0.1 \mathrm{ml}$ of 2,500-IU/ml avian PPD (Veterinary Laboratories Agency, Weybridge, $\mathrm{UK})$. After $72 \mathrm{~h}$, the skin thickness at the injection sites was measured. Results were interpreted according to the recommendations of the Office International des Epizooties [27]. When the change in skin thickness is greater at the avian PPD injection site, the animal was considered positive for mycobacterial species other than the Mycobacterium tuberculosis complex. When increases were observed at both injection sites, the difference between the two reaction sizes was considered. Thus, if the increase in skin thickness at the injection site for bovine PPD (B) was greater than the increase in skin thickness at the injection site for avian PPD (A) i.e. B minus A was less than $2 \mathrm{~mm}$, between 2 and $4 \mathrm{~mm}$, or $4 \mathrm{~mm}$ and above, the animal was classified as negative, suspect, or positive for bovine $\mathrm{TB}$, respectively. 
Citation: Tafess K, Ameni G (2011) Immune Response in Holstein-Zebu Cross and Zebu Calves Vaccinated with Bacillus Calmette-Guérin (BCG) at Bako Agricultural Research Centre, Western Ethiopia. J Vaccines Vaccin 2:122. doi:10.4172/2157-7560.1000122

Page 3 of 5

\section{Data analysis}

Data entered into excel spread sheet and Student's $t$ test was used to compare the mean optical density (ODs) values of IFN- $\gamma$, antibody and skin thicknesses.

\section{Results}

\section{IFN- $\gamma$ response}

In this study, IFN- $\gamma$ response was monitored for about 23 weeks post vaccination in both vaccinated and control group. As it can be seen from Figure 1, in vaccinated calves, IFN- $\gamma$ response was seen to increase starting from week 2 , attaining its peak at $4^{\text {th }}$ week post vaccination. Then it started to drop starting from week 4 (Figure 1) until week 13 after which it attained the steady level.

The means of IFN- $\gamma$ responses to saline, avian and bovine PPDs at different weeks in both vaccinated and non-vaccinated neonates was analyzed. The mean of IFN- $\gamma$ response was significantly $\left(\mathrm{t}_{\text {cal }}=2.85\right.$; $\mathrm{P}<0.05)$ higher in vaccinated (Mean \pm SEM, $0.205 \pm 0.018$ ) group than in non-vaccinated group (Mean \pm SEM, $0.168 \pm 0.008$ ) at week 4 .

Comparison was made in the level of IFN- $\gamma$ between vaccinated group of cross and zebu calves. Thus, longitudinal IFN- $\gamma$ response in the two breed is presented in Figure 2. As it is depicted in Figure 2, the kinetics of IFN- $\gamma$ in the two breeds is almost similar with strong correlation $(r=0.95)$ throughout the study period. The mean of IFN- $\gamma$ response at week 4 was significantly $\left(\mathrm{t}_{\text {cal }}=3.01, \mathrm{P}<0.05\right)$ higher in

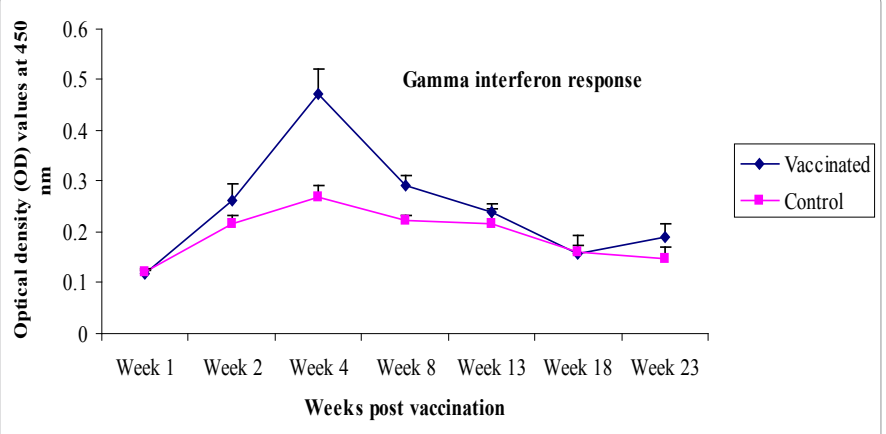

Figure 1: Longitudinal IFN- $\mathrm{y}$ response in vaccinated and non vaccinated calves: In vaccinated calves, IFN- $y$ response was seen to increase starting from week 2 , attaining its peak at $4^{\text {th }}$ week post vaccination. Then it started to drop starting from week 4 until week 13 after which it attained the steady level. The mean of IFN- $y$ response was significantly $\left(\mathrm{t}_{\mathrm{c}}=2.85 ; \mathrm{P}<0.05\right)$ higher in vaccinated (Mean \pm SEM, $0.205 \pm 0.018$ ) group than in non-vaccinated group (Mean \pm SEM, $0.168 \pm 0.008$ ) starting from week 2 to week 13 .

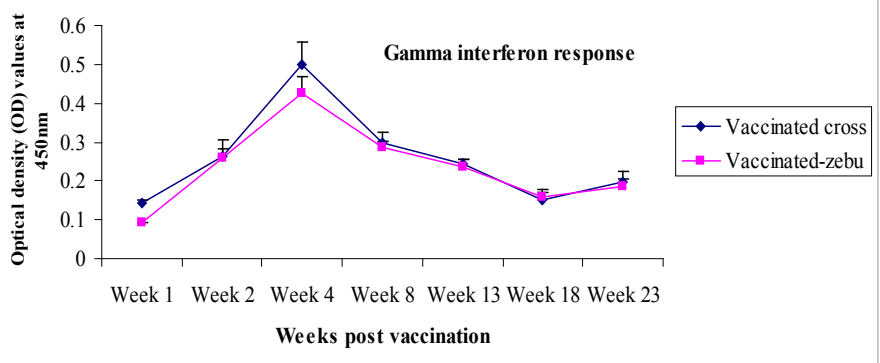

Figure 2: Longitudinal IFN-y in vaccinated cross and zebu calves. The mean of IFN- $y$ response at week 4 was significantly $\left(t_{\text {cal }}=3.01, P<0.05\right)$ higher in vaccinated cross (Mean \pm SEM, $0.217 \pm 0.021$ ) calves than in vaccinated zebu calves (Mean \pm SEM, $0.194 \pm 0.015$ ). Except at week 4 the difference in IFN-y responses was similar in the two breeds. vaccinated cross (Mean \pm SEM, $0.217 \pm 0.021$ ) calves than in vaccinated zebu calves (Mean \pm SEM, $0.194 \pm 0.015$ )

\section{Measurement of immunoglobulin production}

Immunoglobulin production was measured at weeks $3,5,8,13$, and 23 post vaccinations against bovine PPD and MPB83. As can be seen from Table 1 the level of antibody response is below 0.30 throughout the study periods except at week 23 in which there was a detectable level of antibodies in vaccinated cross breeds. There was no observable variation in antibody response in the two breeds of cattle (cross and pure zebu).

\section{Response of comparative intradermal tuberculin test}

Vaccinated and non-vaccinated calves were tested by CIDT at the end of this study; 23 weeks post vaccination. Four of the seven BCG vaccinated calves were turned to be reactors by CIDT while all nonvaccinated were negative. Moreover, the mean CIDT response to bovine PPD was significantly $(\mathrm{P}<0.05)$ higher in vaccinated calves than in non-vaccinated calves (Table 2).

\section{Discussion}

The present study assessed the immune response in Holstein-zebu crossbred and zebu calves following vaccination with BCG. The result demonstrated that the IFN $-\gamma$ response to bovine PPD was measured for several weeks after vaccination. The IFN- $\gamma$ response was low at week 0 both in vaccinated and non-vaccinated calves; then increased sharply between week 2 and 4 attaining peak at week 4 after which it declined rapidly. Similar findings were reported by other workers previously [12-15]. Most of these studies demonstrated that two weeks after BCG vaccination, IFN- $\gamma$ in peripheral blood significantly increases and starts to decline after the $4^{\text {th }}$ week of vaccination and wanes at week 12 post vaccination. As the IFN- $\gamma$ is a key cytokine in the immune response against bovine tuberculosis [16], the release of IFN- $\gamma$ following BCG vaccination could imply the potential of BCG in protecting bovine tuberculosis. Although previous observations of IFN- $\gamma$ responses were made in Bos taurous such as Holstein, in the present study, similar observation was also made in Bos indicus (zebu) breed. Substantiating the implication of induction of IFN- $\gamma$ responses for protection against bovine tuberculosis, experimental and field studies on efficacy of BCG have shown that BCG was found to protect calves from infection with M. bovis $[12,17,14,18,15]$.

Our data indicated significantly $(\mathrm{P}<0.05)$ higher level of IFN- $\gamma$ release in cross breed as compared to the zebu breed in the vaccinated neonates. This finding is similar with results of previous studies conducted in Ethiopia [19,20]. Although such difference in the level of IFN- $\gamma$ response between the two breeds could be due to the difference in the repertoire of the two breeds in recognizing mycobacterial antigens [19], further investigation would be necessary to identify the factors that cause such difference.

Antibody responses were absent or very low in both vaccinated and non-vaccinated calves throughout the study period. Similar findings were reported by earlier studies $[12,20]$ Similarly, Fifis et al. [21] reported the absence of antibody response following experimental inoculation of M. bovis in cattle in the first 18 months post-inoculation. Furthermore, negative correlation was observed between antibody and cell-mediated responses in tuberculosis [22,21].

The result of CIDT at the $23^{\text {rd }}$ week post vaccination demonstrated that the majority of vaccinated calves became reactors. Similarly, Wedlock et al. [23] have reported skin response 15 weeks post BCG 
Citation: Tafess K, Ameni G (2011) Immune Response in Holstein-Zebu Cross and Zebu Calves Vaccinated with Bacillus Calmette-Guérin (BCG) at Bako Agricultural Research Centre, Western Ethiopia. J Vaccines Vaccin 2:122. doi:10.4172/2157-7560.1000122

\begin{tabular}{|l|l|l|l|l|l|}
\hline Weeks & Antigens & $\begin{array}{l}\text { cross } \\
\text { vaccinated }\end{array}$ & $\begin{array}{l}\text { cross non } \\
\text { vaccinated }\end{array}$ & $\begin{array}{l}\text { Zebu } \\
\text { vaccinated }\end{array}$ & $\begin{array}{l}\text { zebu-non- } \\
\text { vaccinated }\end{array}$ \\
\hline Week 3 & PPDa & $0.291 \pm 0.035$ & $0.276 \pm 0.018$ & $0.210 \pm 0.027$ & $0.294 \pm 0.085$ \\
\hline & MPB83 & $0.215 \pm 0.011$ & $0.269 \pm 0.035$ & $0.259 \pm 0.038$ & $0.225 \pm 0.019$ \\
\hline Week 5 & PPDa & $0.261 \pm 0.025$ & $0.269 \pm 0.026$ & $0.282 \pm 0.047$ & $0.254 \pm 0.013$ \\
\hline & MPB83 & $0.263 \pm 0.022$ & $0.247 \pm 0.015$ & $0.265 \pm 0.044$ & $0.257 \pm 0.002$ \\
\hline Week 8 & PPDa & $0.206 \pm 0.028$ & $0.195 \pm 0.030$ & $0.107 \pm 0.002$ & $0.162 \pm 0.010$ \\
\hline & MPB83 & $0.193 \pm 0.005$ & $0.227 \pm 0.013$ & $0.124 \pm 0.005$ & $0.159 \pm 0.019$ \\
\hline Week13 & PPDa & $0.145 \pm 0.008$ & $0.153 \pm 0.011$ & $0.131 \pm 0.009$ & $0.120 \pm 0.013$ \\
\hline & MPB83 & $0.196 \pm 0.014$ & $0.202 \pm 0.018$ & $0.151 \pm 0.019$ & $0.148 \pm 0.018$ \\
\hline Week18 & PPDa & $0.298 \pm 0.039$ & $0.245 \pm 0.022$ & $0.227 \pm 0.033$ & $0.328 \pm 0.037$ \\
\hline & MPB83 & $0.294 \pm 0.028$ & $0.252 \pm 0.012$ & $0.221 \pm 0.007$ & $0.201 \pm 0.003$ \\
\hline Week23 & PPDa & $0.812 \pm 0.303$ & $0.417 \pm 0.075$ & $0.234 \pm 0.023$ & $0.277 \pm 0.027$ \\
\hline & MPB83 & $0.494 \pm 0.117$ & $0.392 \pm 0.062$ & $0.232 \pm 0.018$ & $0.249 \pm 0.015$ \\
\hline
\end{tabular}

Table1: The Means immunoglobulin Responses to Bovine PPD and MPB83 in BCG Cross (vaccinated and Non vaccinated) and Zebu (vaccinated and Non vaccinated) calves.

\begin{tabular}{|c|c|c|c|c|}
\hline Vaccination status & Mean \pm SE & hange in sk & ickness $(\mathrm{mm})$ & Reaction status \\
\hline & PPDA & PPDB* & $\Delta \mathrm{B}-\Delta \mathrm{A}$ & \\
\hline Vaccinated & $1.3 \pm 0.47$ & $3.6 \pm 0.81$ & $2.3 \pm 0.75$ & 4 of $7(57 \%)$ \\
\hline Non vaccinated & $1.0 \pm 0.22$ & $0.6 \pm 0.20$ & $0.7 \pm 0.29$ & 0 of $7(0 \%)$ \\
\hline
\end{tabular}

${ }^{*} \mathrm{P}<0.05, \mathrm{t}, 3.44, \Delta \mathrm{B}$, change in skin thickness to PPDB; $\mathrm{A}$, change in skin thickness to PPDA

Table 2: Comparative intra-dermal tuberculin test response.

vaccination. In the present study, it has further been shown that BCG vaccinated calves have developed memory cell to mycobacterial up until 23 weeks post vaccination. On the other hand, as it has been indicated earlier [16], BCG vaccination interferes with the diagnosis of bovine TB using skin test, which has also been shown in this study as most of the vaccinated calves became reactors after 23 weeks of vaccination. However, the intensity of skin thickness in the vaccinated calves is relatively lower than that recorded in natural infection or experimental infection with pathogenic strain [24].

\section{Conclusion}

BCG induced IFN- $\gamma$ responses in both Holstein-zebu cross and zebu calves although stronger IFN- $\gamma$ response was observed in Holstein-zebu cross breed as compared to the response in zebu, which could suggest the possibility of using BCG for the control of bovine tuberculosis in Ethiopia.

\section{Acknowledgements}

We are highly indebted to the Bako Agricultural Research Centre for allowing us use the experimental calves and the Aklilu Lemma institute of Pathobiology for funding this study.

\section{References}

1. Steele JH (1995) Introduction (part 2 regional and country status reports). In Theon $\mathrm{CO}$ and Steele JH (edt), Mycobacterium bovis infection in animal and Humans. Ames: lowa state Univ press 168-172.

2. Zinsstang J, Schelling E, Roth F, Kazwal R (2006) Economics of bovine tuberculosis: In C.O.Theon and J.H.Steel(edt), Mycobacterium bovis infection in Animals and humans. Blackwell publishing 68-83.

3. Ashford DA, Whitney E, Raghanathan P, Cosivi O (2001) Epidemiology of selected mycobacteria that infect human and other animals. Rev Sci tech 20 105-112.

4. Cosivi O, Grange JM, Dabron CJ, Raviglione MC, Fujikura T, et al. (1998) Zoonotic tuberculosis due to Mycobacterium bovis in developing countries. Emerg Infect Diseas 4: 1-17.

5. Ameni G, Roger F (1998) Study on the epidemiology of bovine tuberculosis in dairy farms (debre Ziet and Ziay, Ethiopia). In: Proeeding of the $12^{\text {th }}$ conference of Ethiopian Veterinary Association (EVA), Addis Ababa, Ethiopia 13-19.

6. Ameni G, Regassa A, Kassa T, Medhin G (2001) Survey on Bovine tuberculosis and its public implication to cattle raising families of Wolaita Soddo, Southern Ethiopia. JAniml prod 1: 55-62.

7. Laval G, Ameni G (2004) Prevalence of bovine tuberculosis in Zebu cattle under traditional animal husbandary in Boji district of western Ethiopia. Revue Med Vet 155: 494-499.

8. Ameni G, Aseffa A, Engers H, Young D, Gordon S, et al. (2007) High prevalence and increased severity of pathology of bovine tuberculosis in Holsteins compared to zebu breeds under field cattle husbandary in central Ethiopia. ClinVaccine Immunol 14: 1356-1361

9. Regassa A, Medhin G, Ameni G (2007) Bovine tuberculosis is more prevalen in cattle owned by famers with active tuberculosis in central Ethiopia. The Vet J 178: 119-125.

10. Ameni G, Hewinson GR, Assefa A, Young DB, Vordermeier MH (2008) Appraisal of interpretation criteria for the comparative intradermal tuberculin test for the diagnosis of bovine tuberclosis in central Ethiopia. ClinVaccine Immunol 15: 1272-1276.

11. Demelash B, Inangolet F, Oloya J, Asseged B, Badaso M, et al. (2008) Prevalence of bovine tuberculosis in Ethiopia slaughter cattle based on post mortem examination. Trop Animl Health Prod 41: 755-765.

12. Buddle BM, De Lisle GW, Pfeffer A, Aldwell FE (1995) Immunologica responses and protection against Mycobacterium bovis in calves vaccinated with a low dose of BCG. Vaccine 13: 1123-1130.

13. Ameni G, Tibbo M (2002) Kinetics of interferon-gamma (IFN-gamma) release in the peripheral blood of calves vaccinated with BCG. J Immunoassay Immunochem 23: 245-253.

14. Hope C, Thom L, Villarreal-ramos B, Vordermeier M, Hewinson G, et al. (2005) Vaccination of neonatal calves with Mycobacterium bovis BCG induces protection against intranasal challenge with virulent $M$. bovis. Clin Exper Immunol 139: 48-56.

15. Ameni G, Vordermeier M, Firdessa R, Aseffa A, Hewinson G, et al. (2011) Mycobacterium tuberculosis infection in grazing cattle in central Ethiopia. The Vet J 188: 359-361.

16. Buddle MB, Parlane AN, Keen LD, Aldwell EF, Pollock MJ, Lightbody K Andersen P (1999) Differentiation between Mycobacterium bovis BCGVaccinated and $M$. bovis-Infected Cattle by Using Recombinant Mycobacteria Antigens. Clin Diagnostic Lab Immunol 6: 1-5.

17. Vordermeier M, Chambers A, Cockle J, Whelan O, Simmon SJ, et al. (2002) Correlation of ESAT-6-Specific Gamma Interferon Production with Pathology in Cattle following Mycobacterium bovis BCG Vaccination against Experimental Bovine Tuberculosis. Infect Immunol 70: 3026-3032.

18. Lopez-Valencia G, Renteria-Evangelista T, de Jesús Williams J, Licea-Navarro A, De la Mora-Valle A, et al. (2011) Field evaluation of the protective efficacy of Mycobacterium bovis BCG vaccine against bovine tuberculosis. Research Vet Sci 88: 44-49.

19. Ameni G, Aseffa A, Engers H, Young D, Hewinson G, et al. (2006) Cattle husbandry in Ethiopia is a predominant factor for affecting the pathology of bovine tuberculosis and gamma interferon responses to mycobacterial antigens. Clin Vaccine Immunol 13: 1030-1036.

20. Tewodros D, Ameni G (2010) Immunogenicity of Bacillus Calmette-Guérin (BCG) in bovine neonates under traditional farming in central Ethiopia. J Immunoassay Immunochem 31: 160-168.

21. Fifis T, Corner AL, Rothel SJ, Wood RP (1994) Cellular and Humoral Immune Responses of Cattle to Purified Mycobacterium bovis Antigens. Scandinavian J Immunol 39: 267-274.

22. Ritacco V, Lopez B, De Kantor IN, Barrera L, Errico F, Nader A (1991) Reciprocal cellular and humoral immune responses in bovine tuberculosis. Res. Vet. Sci. 50: 365-367.

23. Wedlock N, Aldwell EF, Collins MD, De Lisle WG, Wilson T, et al. (1999) Immune Responses Induced in Cattle by Virulent and Attenuated Mycobacterium bovis Strains: Correlation of Delayed-Type Hypersensitivity with Ability of Strains to Grow in Macrophages. Infect Immunol 67: 2172-2177. 
Citation: Tafess K, Ameni G (2011) Immune Response in Holstein-Zebu Cross and Zebu Calves Vaccinated with Bacillus Calmette-Guérin (BCG) at Bako Agricultural Research Centre, Western Ethiopia. J Vaccines Vaccin 2:122. doi:10.4172/2157-7560.1000122

Page 5 of 5

24. Waters RW, Palmer VM, Thacker CT, Payeur BJ, Harris BN, et al. (2006) Immune Responses to Defined Antigens of Mycobacterium bovis in Cattle Experimentally Infected with Mycobacterium kansasii. Clin Vaccine Immuno 13: 611-619.

25. Lyashchenko K, Whelan OA, Greenwald R, Pollock MJ, Andersen P, et al.
(2004) Association of Tuberculin-Boosted Antibody Responses with Pathology and Cell-Mediated Immunity in Cattle Vaccinated with Mycobacterium bovis BCG and Infected with M. bovis. Infect Immun 72: 2462-2467.

26. Office of International Epizootics (2004) Manual of Diagnostic Tests and Vaccines for Terrestrial Animals. 